Proceedings of XIX International Scientific Conference "New Technologies and Achievements in Metallurgy, Material Engineering, Production Engineering and Physics", Częstochowa, Poland, June 7-8, 2018

\title{
The Influence of Recycled Single Polymer Polyester Composites on Gas Permeability
}

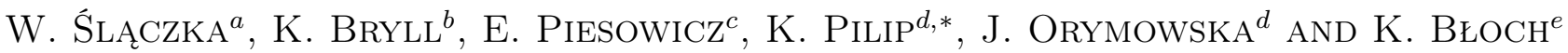 \\ ${ }^{a}$ Maritime University of Szczecin, Faculty of Navigation, Maritime Risk Analysis Center, \\ Wały Chrobrego 1-2, 72-005 Szczecin, Poland \\ ${ }^{b}$ Maritime University of Szczecin, Faculty of Marine Engineering, Department of Marine Engineering Materials, \\ Willowa 2-4, 71-650 Szczecin, Poland \\ ${ }^{c}$ West Pomeranian University of Technology, Institute of Materials Science and Engineering, \\ Faculty of Mechanical Engineering and Mechatronics, al. Piastów 19, 70-310 Szczecin, Poland \\ ${ }^{d}$ Maritime University of Szczecin, Faculty of Marine Engineering, Wały Chrobrego 1-2, 72-005 Szczecin, Poland \\ ${ }^{e}$ Czestochowa University of Technology, Faculty of Materials Processing Technology and Applied Physics, \\ Department of Functional Materials, Czestochowa, Poland
}

\begin{abstract}
Single polymer polyester composites were recycled by compression moulding and extrusion. The recycled products were formed into films of $5 \mathrm{~cm}^{2}$ surface area and about $250 \mu \mathrm{m}$ thick. The paper has presented the influence of recycled materials on the permeability of gases $\left(\mathrm{O}_{2}, \mathrm{CO}_{2}, \mathrm{~N}_{2}\right)$ and water vapour through the walls of the produced films. The influence of processing on the gas barrier of thin films was also determined. The results obtained were compared with the properties of commercial materials.
\end{abstract}

DOI: 10.12693/APhysPolA.135.246

PACS/topics: recycling, film, recycled materials, permeability of film, extrusion, compression moulding, polyester

\section{Introduction}

Permeability (penetrability), solubility and diffusion are the characteristics of a polymer that affect its barrier properties.

Permeation is a mass transport process, wherein the molecules pass through the polymer layer, from the "external environment" to the "internal" one or vice versa, due to diffusion [1-3].

The occurrence of a barrier property is particularly desirable when using polymers in industry, especially in packaging applications. Advances in the area of packaging are related to efforts to improve the quality of packaged goods, and extend their "best before" date while increasing the packaging's usability and marketing functions. In order to ensure the quality of packaged goods, not only that of food products, it is necessary to provide appropriate barrier properties against gases and water vapour [1-4].

Barrier properties can be developed using an appropriate technology for the manufacture and processing of polymer materials and/or composites. The orientation of macromolecules, which occurs during the processing of semicrystalline materials, improves the order of the polymer's structure which decreases the permeability of the polymer to gas molecules, in particular oxygen and $\mathrm{CO}_{2}$.

*corresponding author; e-mail: k.pilip@am.szczecin.pl
Therefore, it is important to choose an appropriate method of processing and managing the waste from the packaging industry, as it is estimated that $1,005,000$ tonnes of materials were used for this purpose in 2016 [5].

The paper has investigated the influence of the method of material recycling of single-polymer polyester composites on the barrier properties of a polyester film.

\section{The material under study and the study method}

The material under study was the film obtained from the material recycling of single-polymer polyester composites [6], namely a composite of a poly(ethylene terephthalate) matrix modified with glycol (PETG) and reinforced with $20 \%$ by weight of poly(ethylene terephthalate) (PET) and this was the material that was processed. These composites were recycled using two methods: blown extrusion (material A) and press moulding (material B). The study was conducted with 12 samples of each material. The thickness of the film was determined using a precise MG-401 thickness meter (made by Elmetron, PL) which has an accuracy of $\pm 1 \mu \mathrm{m}$. The measurement results have been presented in Table I.

The water vapour permeability was determined by the weight method according to PN-ISO 2528:2000. The gas permeability was measured with the use of the apparatus for measuring barrier properties that makes use of the manometric method in accordance with ASTM D1434-82. 
TABLE I

Basic parameters of the studied materials, i.e. thickness and surface area.

\begin{tabular}{c|l|c|c|c}
\hline \hline Material & $\begin{array}{c}\text { Recycling } \\
\text { method }\end{array}$ & $\begin{array}{c}\text { Surface area } \\
\text { of the sample } \\
{\left[\mathrm{cm}^{2}\right]}\end{array}$ & $\begin{array}{c}\text { Average } \\
\text { thickness } \\
{[\mu \mathrm{m}]}\end{array}$ & $\begin{array}{c}\text { Density } \\
{\left[\mathrm{g} / \mathrm{cm}^{3}\right]}\end{array}$ \\
\hline A & extrusion & 5 & $248 \pm 2$ & 1.2426 \\
\hline B & pressing & 5 & $253 \pm 1$ & 1.2387
\end{tabular}

\section{Results and analysis}

The assessment of the barrier properties of the obtained films is of great importance for application purposes, as it makes it possible to choose the correct recycling method for single-polymer polyester composites. This paper has investigated the ability of gas to penetrate through thin films made by the two methods. The averaged results of the investigations have been shown in Figs. 1 and 2. Analysis of the results showed an increase in the pressed materials' permeability to water vapour by approximately $11 \%$, in comparison with the extruded film. Similarly it could be observed that the barrier properties, with regard to the permeability of the pressed film to gases, decreased by about $10 \%$. This is probably related to the reorientation of the macromolecules that occurs during the processing (extrusion by blowing), which increased the order of the polymer structure. The reorientation decreased the permeability of the film to water vapour and gases, especially oxygen and $\mathrm{CO}_{2}$.

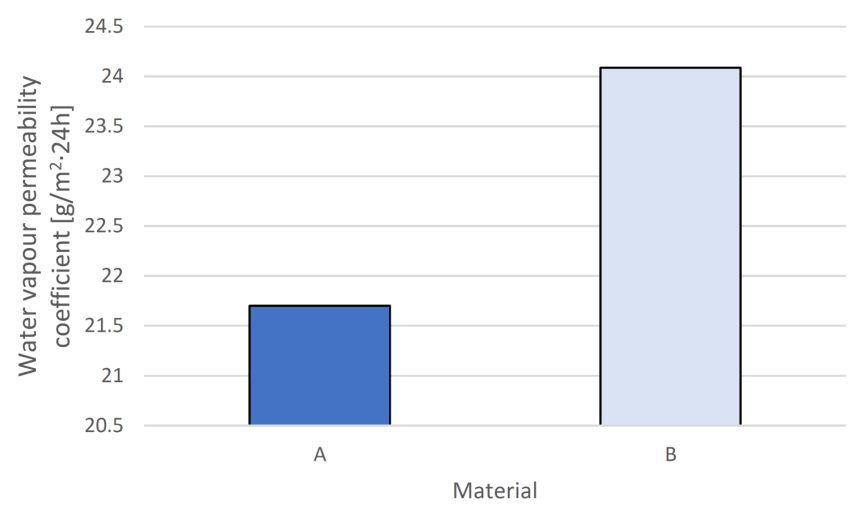

Fig. 1. Water vapour permeability coefficient for the studied materials.

Gas penetrability is associated with the structure of the polymer. The polyester mixture studied was a semicrystalline material and, like most polymers of this type, has a decreasing ability to transmit gases with an increase in its crystallinity. There are two explanations for this phenomenon. Firstly, the appearance of impermeable crystallites reduces the amount of the amorphous phase (capable of transmitting the gas). Secondly, the crystallites extend the path of gas penetration through the polymer.

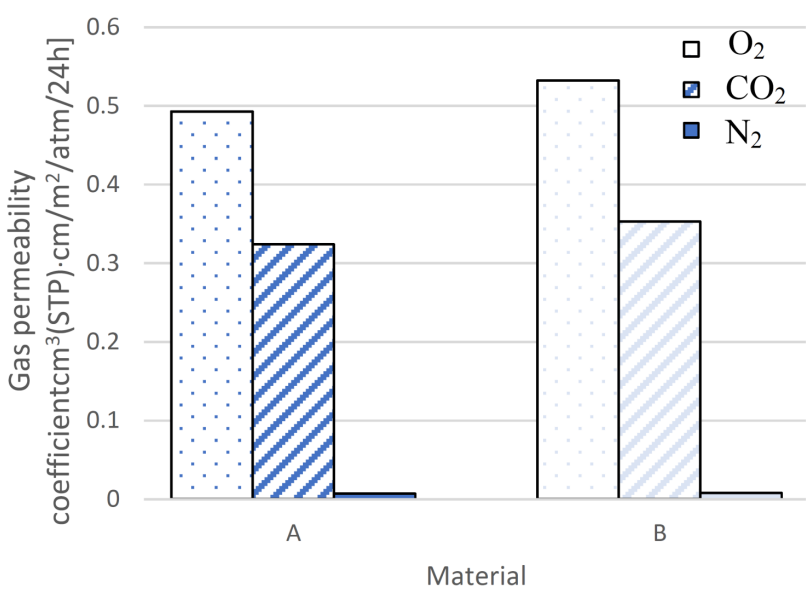

Fig. 2. Gas permeability coefficient for the investigated materials.

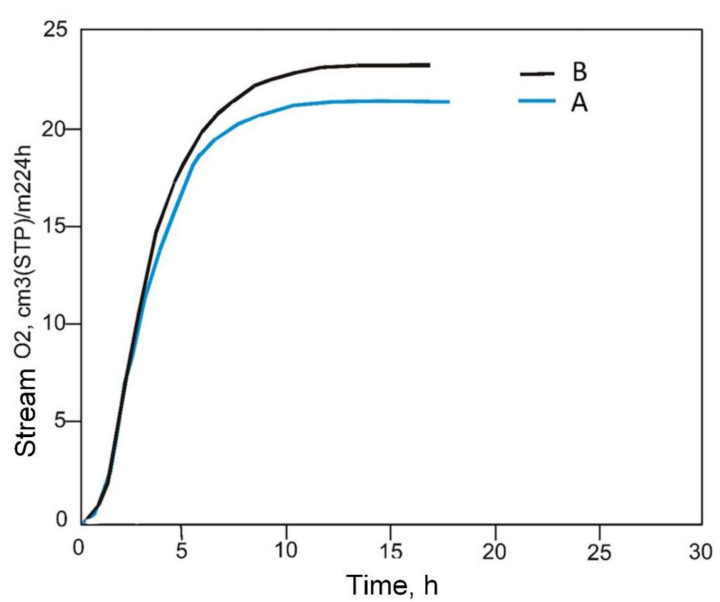

Fig. 3. Oxygen permeation for the studied materials, as a function of time.

The gas permeability increased rapidly as a function of time for the materials under study, creating a similar characteristic, as can be seen in the graph (Fig. 3). The sharp increase meant that the gas molecules in the sample were non-uniformly scattered. The stream of transmitted oxygen only stabilised when the scattering of the gas particles in the sample became uniform.

\section{Conclusion}

The absorbed agent (gas, water vapour) was transported in the polymers as a result of a combination of such phenomena as:

- decomposition of absorbed gas molecules on the polymer's surface,

- diffusion of molecules through the polymer (caused by the concentration gradient),

- desorption from the surface of the material (release of gas from the polymer). 
The gas molecules could also move within the polymer matrix due to the free space in the matrix caused by the random structure of the polymer. Various defects, inclusions and cracks may also be the cause of these free spaces. The absorbed gas is dissolved in a solid, which is a thin layer of the polymer. This is a thermodynamic transition, determined by the change of enthalpy (total heat) of the molecules decomposed in the polymer matrix and their occupancy of the free space. From the literature [7-10] the results showed that molecules are more readily and quickly absorbed by a polymer with more free space than by one with less free space. This was confirmed by certain polymers in a glass-like state with an ordered structure. The free volume of a polymer also depends on its nature and physical state, including the orientation and the physical effect of ageing. These spaces form the basis of diffusion in all polymers.

The purpose of this study was to determine the impact of the method of material recycling of single-polymer polyester composites on the barrier properties of the obtained film. The results obtained for the manufactured materials (for both methods) were consistent with the assumptions presented in the literature [7-11]. The measurements showed that due to the orientation of the macromolecules being a result of blown extrusion, an improvement of the barrier properties was observed in comparison with a film produced in material recycled by pressing. This has proved that recycling is advisable and has a positive impact on the barrier properties of the recycled materials.

\section{Acknowledgments}

The research presented in this article was carried out under the Grant of the Ministry of Science and Higher Education of Poland nr 1/S/IESO/17 performed at the Maritime University of Szczecin, Poland.

\section{References}

[1] Diffusion in Polymers, Eds. J. Crank, G.S. Park, Academic Press, London 1968.

[2] F. Samperi, C. Puglisi, R. Alicata, G. Moutaudo, Polym. Degradat. Stabil. 83, 3 (2004).

[3] G. Flodberg, I. Helland, L. Thomsson, S. Bodil Fredriksen, Europ. Polym. J. 63, 217 (2015).

[4] M. Żenkiewicz, J. Richert, Polym. Test. 27, 835 (2008).

[5] Plastics Europe Polska, Annual Report 2016.

[6] K. Bryll, K. Gawdzińska, M. Nabiałek, P. Pawłowska, Rev. Chim. 68, 2034 (2017).

[7] E.A. McGonigle, J.J. Liggat, R.A. Pethrick, S.D. Jenkins, J.H. Dely, D. Hayward, Polymer 42, 2413 (2001).

[8] E. Piesowicz, Z. Rosłaniec, Inżynieria Materiałowa 33, 556 (2012) (in Polish).

[9] E. Baer, Y.S. Hu, R.Y.F. Liu, D.A. Schiraldi, A. Hiltner, Polym. Mater. Sci. Eng. 89, 19 (2003).

[10] A. Polyakova, E.V. Stepanow, D.A. Sekelik, D.A. Schiraldi, A. Hiltner, E. Baer, J. Polym. Sci. B Polym. Phys. 39, 1911 (2001).

[11] L. Chybowski, K. Gawdzińska, Advances in Intelligent Systems and Computing, Vol. 445, Springer Int. Publ., 2016, p. 701. 